\title{
Perancangan dan realisasi aplikasi manajemen kegiatan asrama berbasis Android dan RFID
}

\author{
Asep Maulana ${ }^{*}$, Rahmawati Hasanah ${ }^{2}$, Andry Haidar ${ }^{3}$ \\ 1,2,3 Jurusan Teknik Elektro, Politeknik Negeri Bandung \\ Jl. Gegerkalong Hilir, Ciwaruga, Kec. Parongpong, Kabupaten Bandung Barat, Jawa Barat, Indonesia \\ 1*asep.maulana.tcom417@polban.ac.id, ${ }^{2}$ rahmawati@polban.ac.id, ${ }^{3}$ andry.haidar@polban.ac.id
}

\begin{abstract}
ABSTRAK
Manajemen kegiatan asrama diperlukan sebagai media informasi bagi anggota asrama dalam mengetahui informasi dan kegiatan selama berada di asrama. Saat ini, di asrama kampus Polban, penyampaian informasi seputar asrama seperti kegiatan, pendataan paket, pencatatan presensi, dan pelaporan fasilitas yang bermasalah masih menggunakan media konvensional seperti menghubungi pengurus secara langsung maupun papan informasi. Selain itu data-data asrama juga masih berdasarkan paper based sehingga rentan terhadap keamanan data. Pada penelitian ini, dibuat perancangan dan realisasi aplikasi manajemen kegiatan asrama berbasis Android dan Radio Frequency Identification (RFID). Sistem ini diperuntukkan bagi penghuni asrama agar lebih mudah dalam mengakses pengingat kegiatan, informasi presensi, informasi kiriman paket, pelaporan fasilitas yang rusak, dan monitoring jumlah mahasiswa. Hasilnya, pada hardware sistem presensi, perangkat dapat melakukan presensi dengan waktu tidak lebih dari 3 detik pada setiap ID kartu dengan jarak pembacaan maksimal $3 \mathrm{~cm}$ dari permukaan perangkat. Integrasi antara perangkat presensi dengan aplikasi Android tidak lebih dari 3 detik pada waktu sebelum presensi dan tidak lebih dari 6 detik pada waktu presensi. Aplikasi Android telah diuji dari total 24 poin tanggapan yang diberikan kepada responden, $8,33 \%$ menyatakan cukup, 83,33\% menyatakan baik, dan $8,33 \%$ menyatakan sangat baik.
\end{abstract}

Kata kunci: manajemen, RFID, asrama, presensi, Android

\begin{abstract}
Management of dormitory activities is needed as a medium of information for dormitory members to find out information and activities while in the dormitory. Currently, in the Polban campus dormitory, the delivery of information about dormitories such as activities, package data collection, attendance recording, and reporting of problematic facilities still uses conventional media such as contacting the management directly or information boards. In addition, dormitory data is still based on paper so it is vulnerable to data security. In this study, the design and realization of an Android-based dormitory activity management application and Radio Frequency Identification (RFID) was made. This system is intended for dormitory residents to make it easier to access activity reminders, attendance information, package delivery information, reporting of damaged facilities, and monitoring the number of students. As a result, on the presence system hardware, the device can make a presence in no more than 3 seconds on each ID card with a maximum reading distance of $3 \mathrm{~cm}$ from the surface of the device. The integration between the presence device and the Android application is no more than 3 seconds before the presence and no more than 6 seconds at the time of the presence. The Android application has been tested from a total of 24 response points given to respondents, $8.33 \%$ said it was sufficient, $83.33 \%$ said it was good, and $8.33 \%$ said it was very good.
\end{abstract}

Keywords: management, RFID, dormitory, attendance, Android

\section{PENDAHULUAN}

Asrama mahasiswa Polban adalah tempat tinggal mahasiswa yang dikelola oleh kampus Politeknik Negeri Bandung (Polban) melalui kepala asrama. Asrama ini diperuntukkan bagi mahasiswa baru dengan status mahasiswa Bidikmisi dan atau mahasiswa dengan UKT1/UKT2 [1]. Dalam pengelolaan manajemennya sendiri, terdapat penyampaian informasi seputar asrama seperti kegiatan rutin asrama, proses presensi, dan informasi kiriman paket dengan menggunakan cara konvensional. Termasuk diantaranya, informasi pendataan paket dan sistem pelaporan fasilitas yang rusak. Pada praktiknya, penyampaian informasi tersebut masih menggunakan media chatting seperti 
WhatsApp dan Line. Hal ini mengurangi efektifitas pada penyampaian informasi. Selain itu, tidak adanya sistem pengontrolan kapasitas asrama yang diperlukan untuk mengetahui jumlah anggota asrama yang ada di dalamnya. Hal ini tentunya sangat diperlukan mengingat pandemi yang terjadi saat ini. Dengan demikian diperlukan sebuah sistem baik berupa aplikasi maupun perangkat keras yang bertujuan untuk mempermudah pengelolaan kegiatan di asrama.

Terdapat beberapa hasil penelitian yang dapat diimplementasikan pada aplikasi manajemen kegiatan asrama ini. Seperti karya dari M. R. Sali [2] berupa aplikasi yang dapat dijalankan pada smartphone Android dengan memanfaatkan Firebase real-time database untuk memudahkan masyarakat melihat jadwal kajian secara real-time. Lalu ada karya dari G. Richard [3] yaitu perancangan aplikasi pemesanan makanan dibuat dengan menerapkan teknologi Firebase berbasis Android sehingga dapat mempermudah pelanggan dalam melakukan proses pemesanan makanan pada Warung Lawas tanpa harus menunggu lama. Lalu ada karya dari E. K. Siagian [4] yaitu aplikasi yang mampu menyampaikan informasi, mengelola data (penghuni, pindah kamar, serah terima kunci, paket kiriman, tamu, dan komplain), serta penghuni asrama dapat menerima informasi. Selanjutnya, karya dari Y. Darnita [5] yaitu aplikasi yang menghadirkan pemberitahuan secara otomatis sehingga dapat mempermudah mahasiswa untuk mendapatkan jadwal perkuliahan langsung dari dosen yang bersangkutan.

Pada bagian perangkat keras, terdapat beberapa penelitian terdahulu yang dapat diimplementasikan seperti karya dari G. Santoso [6] yaitu membuat suatu sistem keamanan yang dapat bekerja secara otomatis, yaitu dapat membuka pintu dengan otomatis menggunakan Android dan RFID sebagai input dan juga sebagai kontrolnya. Selanjutnya karya dari K. Prasetyo [7] yaitu sistem presensi pegawai dengan RFID berbasis Internet of Things (IoT). Hasilnya, pembacaan RFID berhasil dilakukan dengan baik pada jarak 3-4 cm. Data presensi dapat tersimpan secara otomatis pada database pada saat melakukan presensi. Pada penelitian selanjutnya yaitu karya dari A. N. Asykin [8] yaitu sistem absensi berbasis mikrokontroler Arduino dengan RFID berhasil dirancang dan dibangun. Algoritma pengiriman data hasil pembacaan tag identitas kartu yang terbaca oleh RFID reader telah berhasil ditentukan sesuai dengan kebutuhan cara kerja alat. Selanjutnya, karya dari A. Sopa [9] yaitu penerapan teknologi RFID pada sistem pencatatan kehadiran yang dapat mencatat jam masuk serta jam keluar pada website setelah E-KTP terbaca oleh sistem. Lalu karya dari S. S. Chandra [10] berupa sistem akses RFID pada laboratorium sistem kontrol yang didukung oleh aplikasi mobile agar admin (kepala laboratorium) dapat memantau pengguna laboratorium pada hari itu dan juga mengendalikan pintu. Terakhir, penelitian E. Prasetyo [11] yaitu sistem pengganti absensi kertas yang digunakan dengan suatu sistem portabel yang menggunakan kartu RFID sebagai identifikasi mahasiswa.

Adapun tujuan dari penelitian ini adalah membuat aplikasi Android "Asrama-Ku" yang berfungsi untuk mempermudah manajemen anggota asrama Polban dengan menyediakan informasi seperti informasi kegiatan asrama, informasi tentang data paket anggota, dan sarana pelaporan fasilitas yang mengalami masalah dengan dilengkapi perangkat sistem presensi menggunakan RFID yang terintegrasi dengan aplikasi tersebut. Berbeda dengan penelitian sebelumnya, pada penelitian ini terdapat sistem yang terdiri dari perangkat hardware berupa sistem presensi berbasis RFID dan perangkat software berbasis Android yang terintegrasi sehingga pengelolaan manajemen asrama akan lebih efektif.

\section{METODE PENELITIAN}

\subsection{Perancangan Software Aplikasi Android}

Pada Gambar 1 terdapat dua aktor yang berperan pada sistem aplikasi manajemen asrama yaitu pengurus asrama sebagai admin dan anggota asrama sebagai pengguna aplikasi. Pengurus asrama sebagai admin dapat melakukan hapus data, cek profil, cek riwayat absen, input paket, input reminder, melihat reminder, dan menanggapi laporan dari anggota asrama. Sementara anggota asrama sebagai user dapat melakukan cek profile, cek riwayat presensi, menerima paket dan mengkonfirmasinya, serta melihat reminder. Semua proses yang dapat dilakukan oleh pengurus maupun anggota harus melakukan login terlebih dahulu agar dapat melakukan activity yang ditunjukkan pada diagram use case. Apabila pengguna tidak dapat melakukan login maka pengguna dapat melakukan register akun terlebih dahulu. 


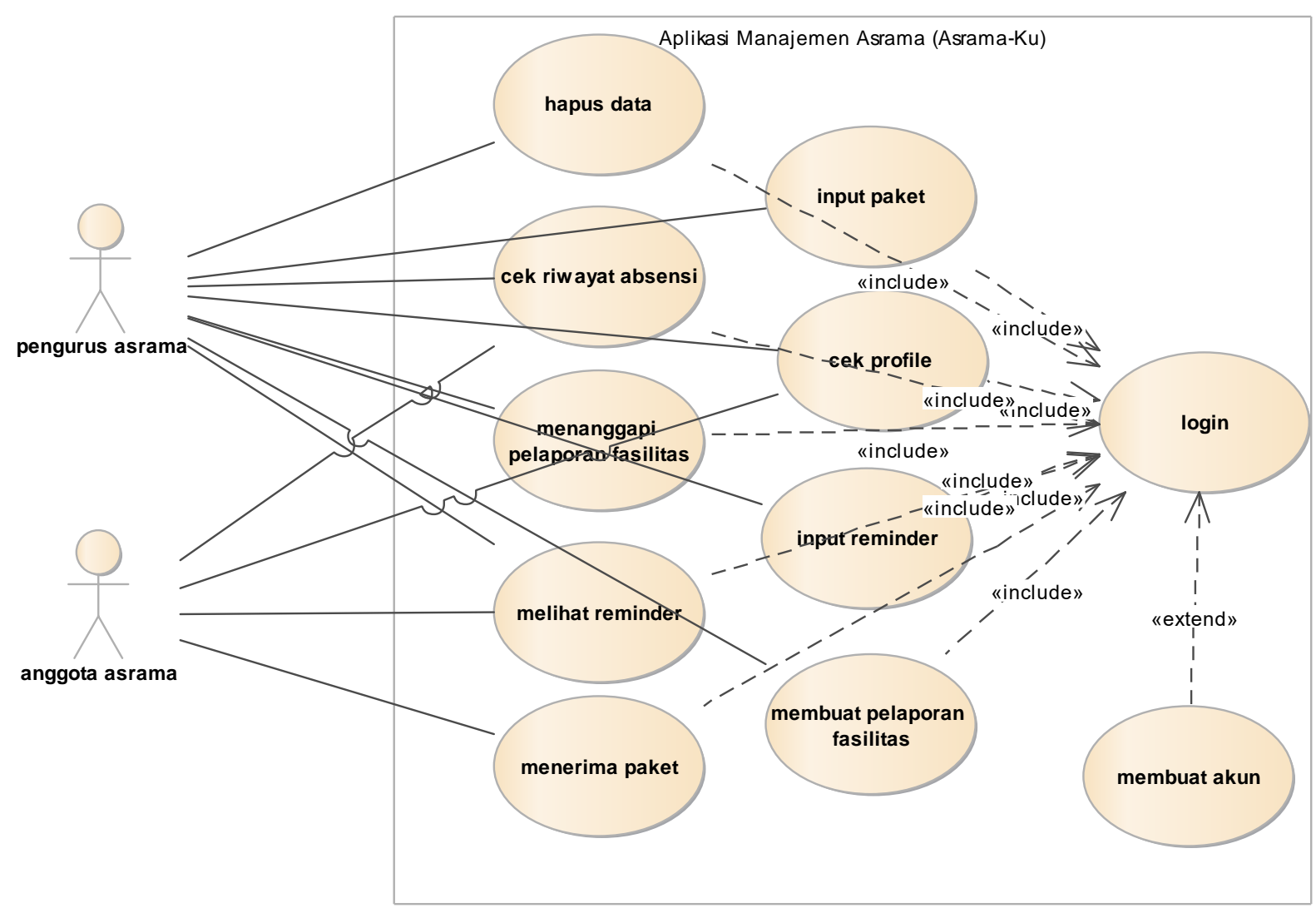

Gambar 1. Use case diagram

Gambar 2. menunjukkan class users yang mempunyai atribut dengan operasi yang dapat dilakukan yaitu login(). Users class merupakan super class dari class anggota asrama dan class pengurus asrama sehingga kedua class tersebut mewarisi seluruh atribut dan method yang dimiliki oleh users class. Pada class anggota asrama, atribut yang dimilikinya yaitu access level dengan nilai false yang menunjukan bahwa user tersebut merupakan anggota asrama. Sedangkan untuk pengurus asrama, access level-nya akan bernilai true. Untuk anggota asrama mempunyai hubungan aggregation dan composition. Hubungan aggregation dengan class presensi dengan multiplisitas one to many dimana class ini merupakan hasil dari sistem perangkat presensi yang mana hubungan aggregation ini berarti class presensi bisa berdiri sendiri tanpa harus adanya class anggota asrama dan anggota asrama dapat memiliki banyak presensi tidak hanya hari itu saja. Sementara hubungan composition dengan class reminder, laporan, dan paket dengan multiplisitas one to many dengan class anggota asrama sebagai parent dan class lainnya sebagai children. Hubungan ini merupakan hubungan yang saling terikat dimana ketika salah satu class dihapus maka class lain juga akan terhapus. Hubungan selanjutnya yaitu hubungan dependency pada class riwayat laporan ke laporan dan paket terkonfirmasi ke paket. Hubungan ini mengakibatkan perubahan data pada elemen yang ditujunya. Pada class pengurus terdapat hubungan aggregation dan composition. Hubungan composition dengan class paket, reminder, dan laporan dengan multiplisitas one to many, sementara hubungan aggregation dengan class presensi dengan multiplisitas one to many. Adapun realisasi aplikasi Android ditujukan dengan beberapa menu yaitu diantaranya seperti yang ditunjukkan pada Gambar 3. 


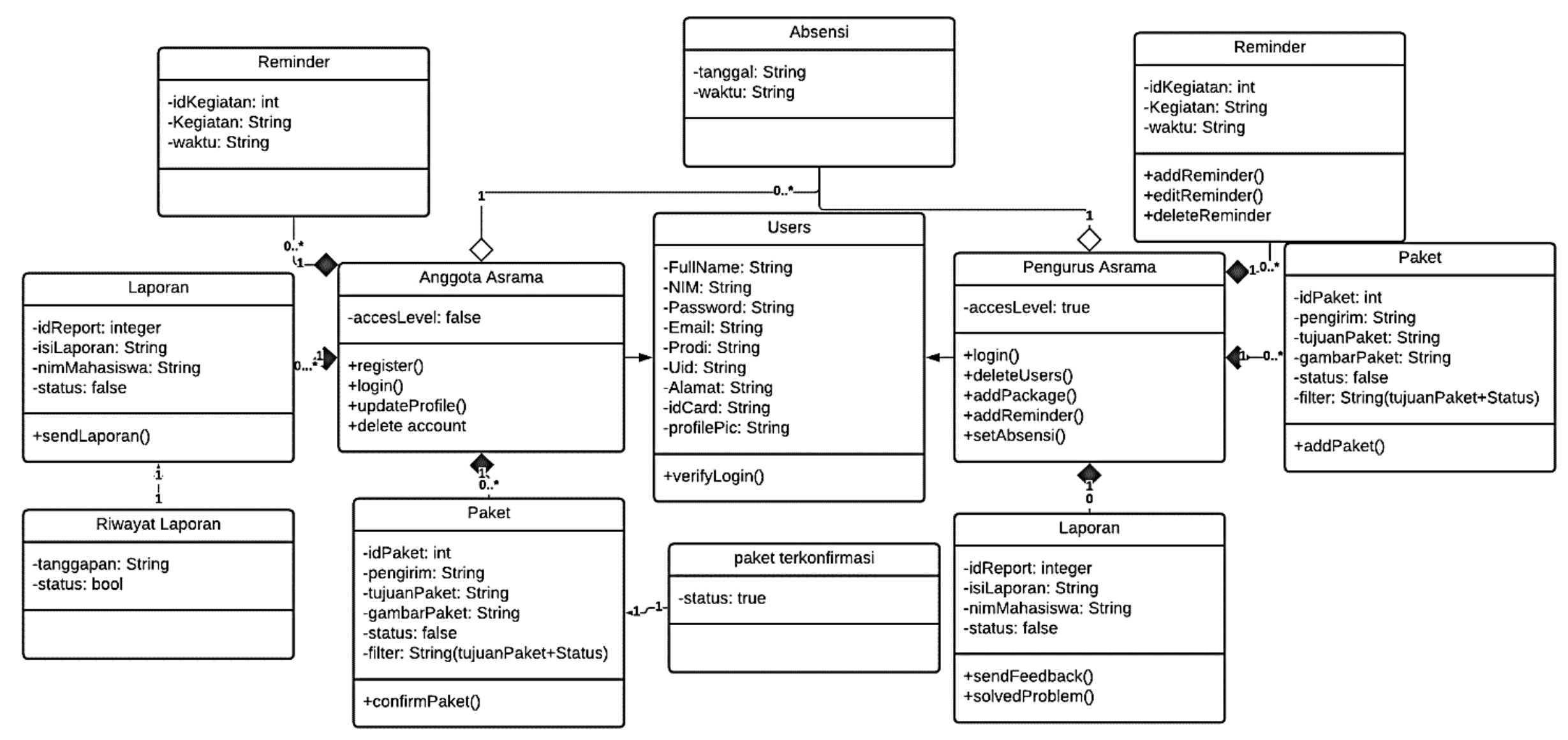

Gambar 2. Class diagram aplikasi 


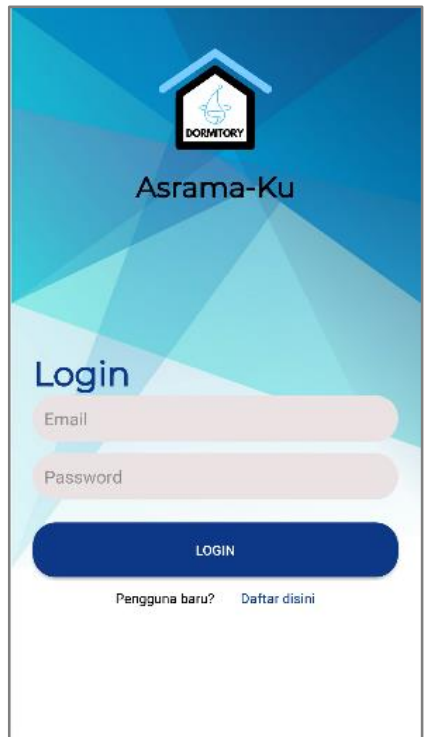

(a) Tampilan login

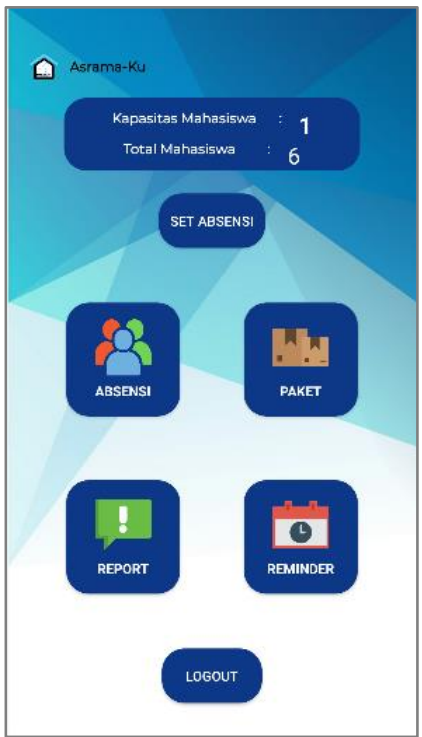

(d) Menu utama admin

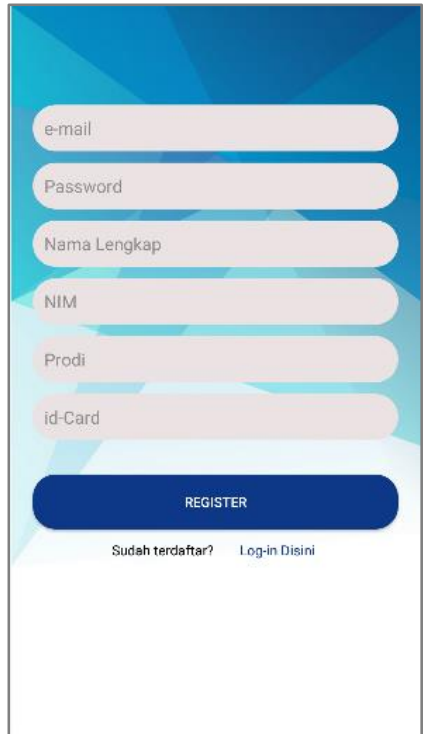

(b) Tampilan register

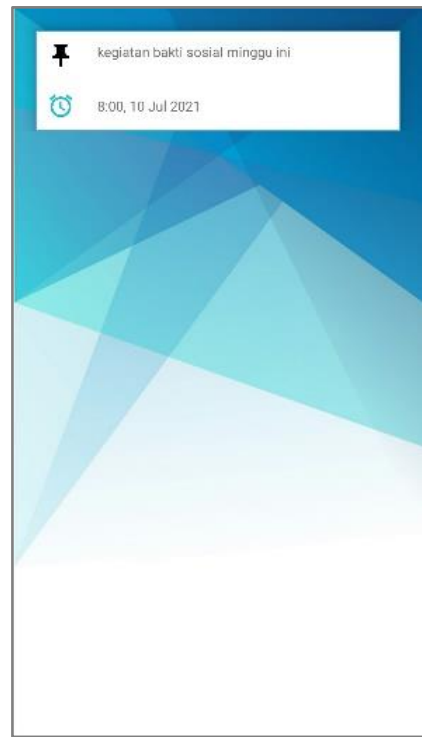

(e) Tampilan reminder

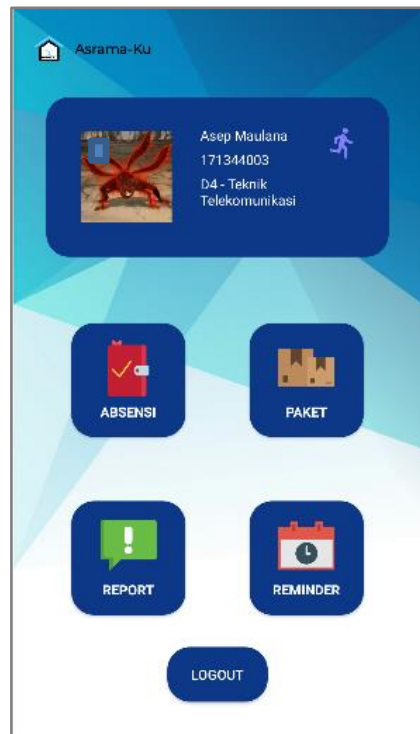

(c) Menu utama user

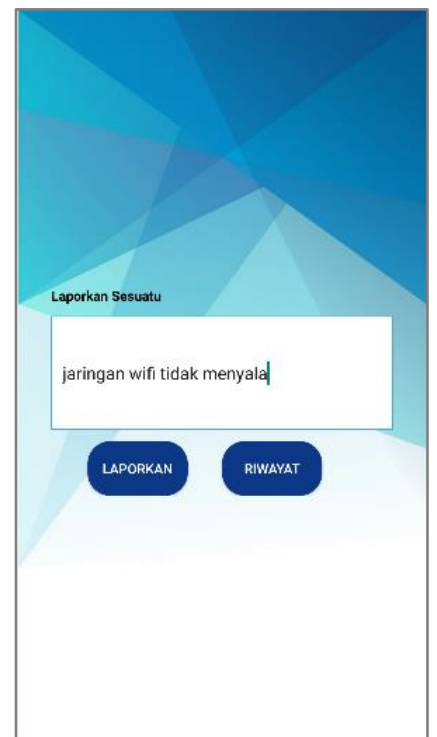

(f) Tampilan pelaporan

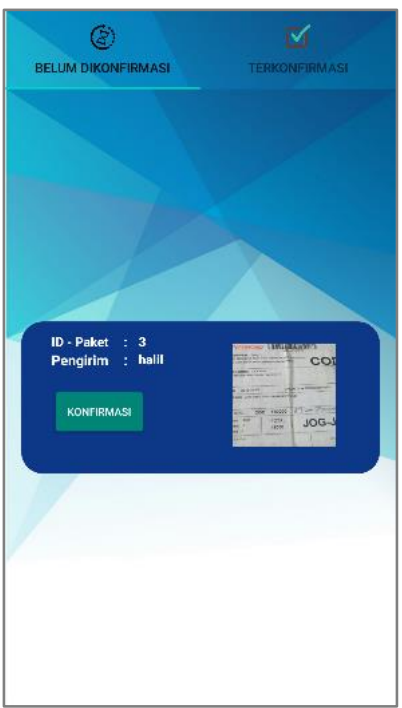

(g) Tampilan paket

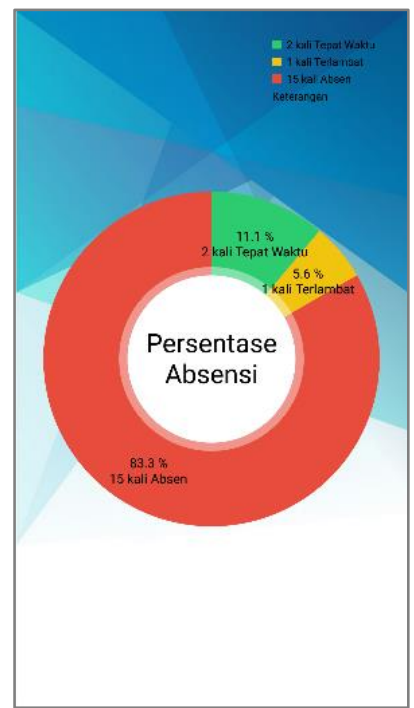

(h) Tampilan persensi

Gambar 3. Realisasi aplikasi Android 


\subsection{Perancangan Hardware Sistem Presensi RFID}

Gambar 4 merupakan diagram blok perangkat presensi RFID. Pada diagram tersebut, input data yang berasal dari RFID card masuk ke sensor RC522. Kemudian data yang diperoleh sensor tersebut masuk ke mikrokontroler NodeMCU ESP8266. Selanjutnya data dikirim oleh mikrokontroler ke server di mana perangkat mikrokontroler ini sudah dilengkapi dengan modul WiFi. Apabila data pada RFID card sudah terdaftar di sistem, maka indikator LCD akan memberitahu bahwa pengguna berhasil absen. Kemudian data waktu proses presensi akan dicatat dan disimpan di Firebase. Sementara apabila data RFID card tidak terdaftar, maka buzzer akan menyala serta LCD akan memberitahu bahwa data tidak terdaftar. Pada sisi server, semua data presensi anggota asrama dapat dilihat oleh admin, sedangkan user dapat melihat datanya sendiri melalui Aplikasi. Adapun skema rangkaian elektronik yang dirancang dapat dilihat pada Gambar 5.

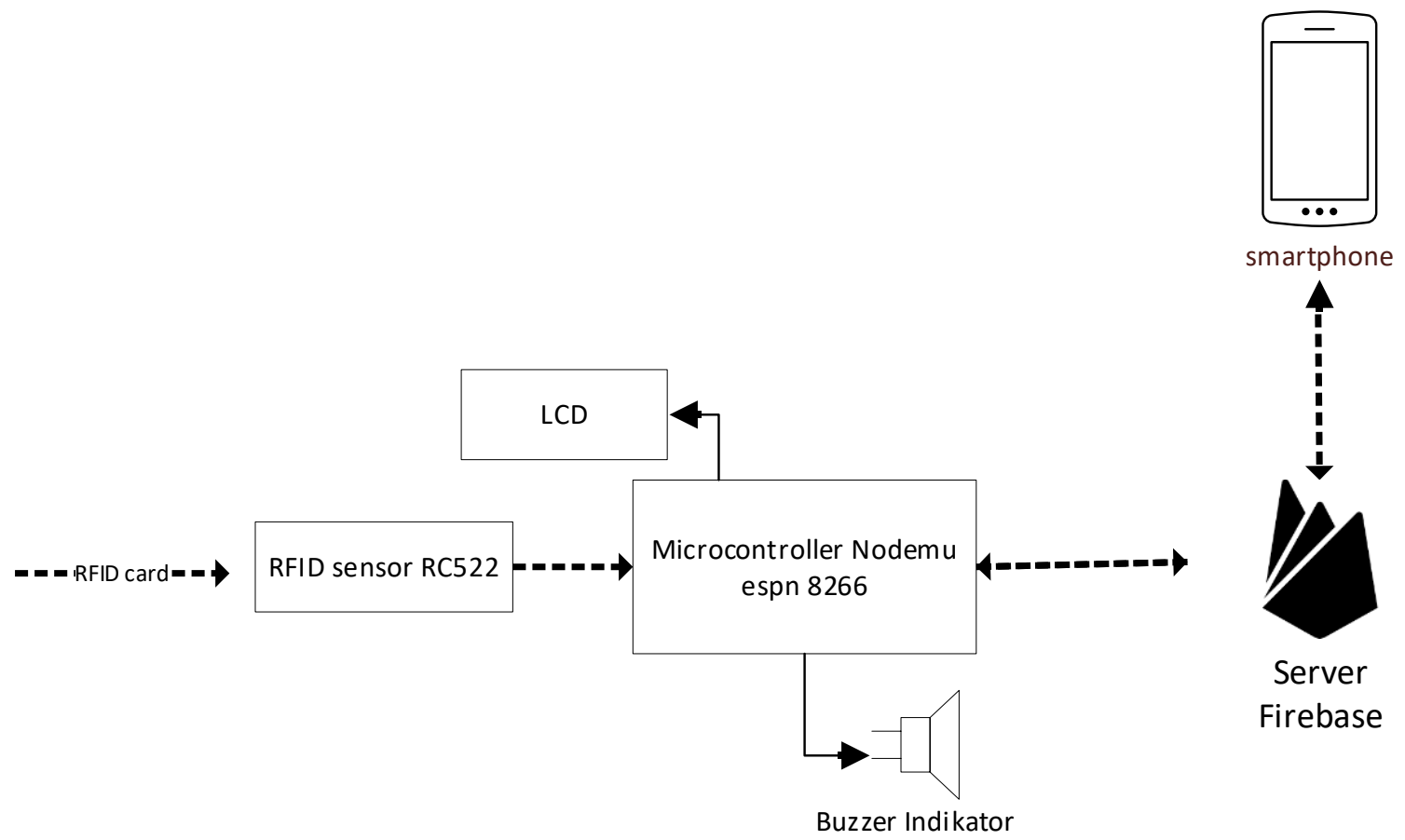

Gambar 4. Blok diagram perangkat presensi

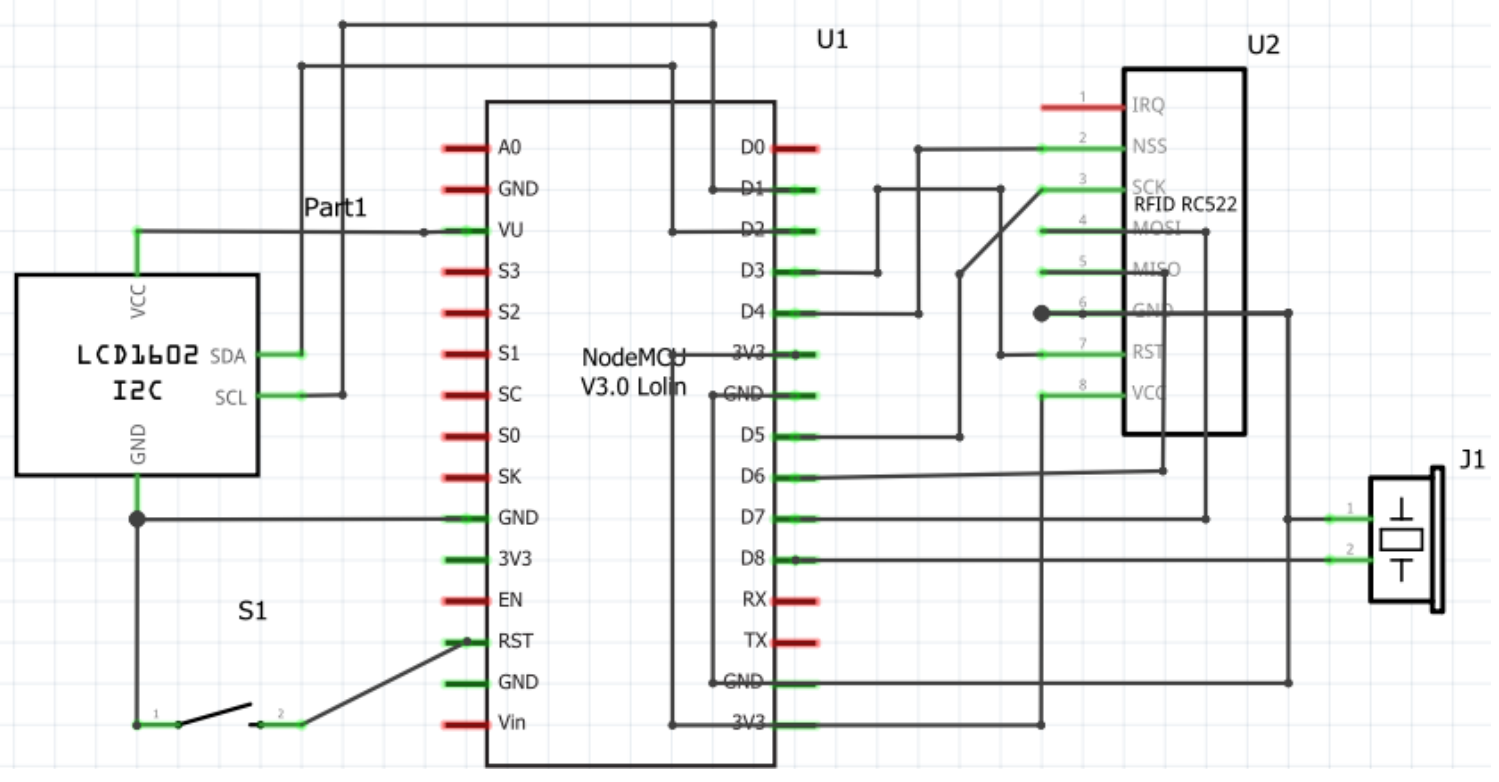

Gambar 5. Skema elektronik sistem 


\subsection{Perancangan Algoritma}

Gambar 6 merupakan flowchart dari perangkat presensi. Proses dimulai dengan mengkoneksikan sistem dengan jaringan WiFi. Selanjutnya, sistem akan memulai inisialisasi ke Firebase untuk menyimpan dan mengambil data di Firebase. Jika Firebase sudah diinisialisasi maka akan ditanyakan kembali apakah inisialisasi Firebase sudah terhubung atau belum. Jika "ya", maka program akan menuju ke proses selanjutnya, namun jika inisialisasi ke firebase terputus, sistem akan mengkoneksikan kembali ke Firebase. Kemudian alat membaca input proses yang berasal dari kartu RFID yang terbaca.

Selanjutnya pada proses decision akan ditanyakan apakah data tersebut sudah terdaftar sistem. Jika tidak maka proses akan selesai dan output pada LCD akan menampilkan jika ID card ditolak dan buzzer akan menyala selama 1 detik. Jika ID card terdaftar, maka data akan diteruskan ke proses selanjutnya yaitu proses decision. Data akan ditanya apakah data masuk tersebut melakukan presensi sesuai dengan waktunya yaitu pada jam $17.00-18.00$ WIB. Sesuai yang tertera pada buku saku asrama bahwa anggota asrama harus melaksanakan setidaknya tiga kali shalat berjamaah di asrama yaitu Magrib, Isya, dan Shubuh. Maka sebelum waktu magrib, mahasiswa harus berada di asrama. Jika tidak maka data tersebut hanya akan dicatat status keberadaannya. Jika waktunya sesuai maka data akan dicatat waktu presensinya dan status keberadaannya. LCD akan mengeluarkan output dengan tampilan "access granted" dan buzzer akan menyala dua kali lalu proses selesai.

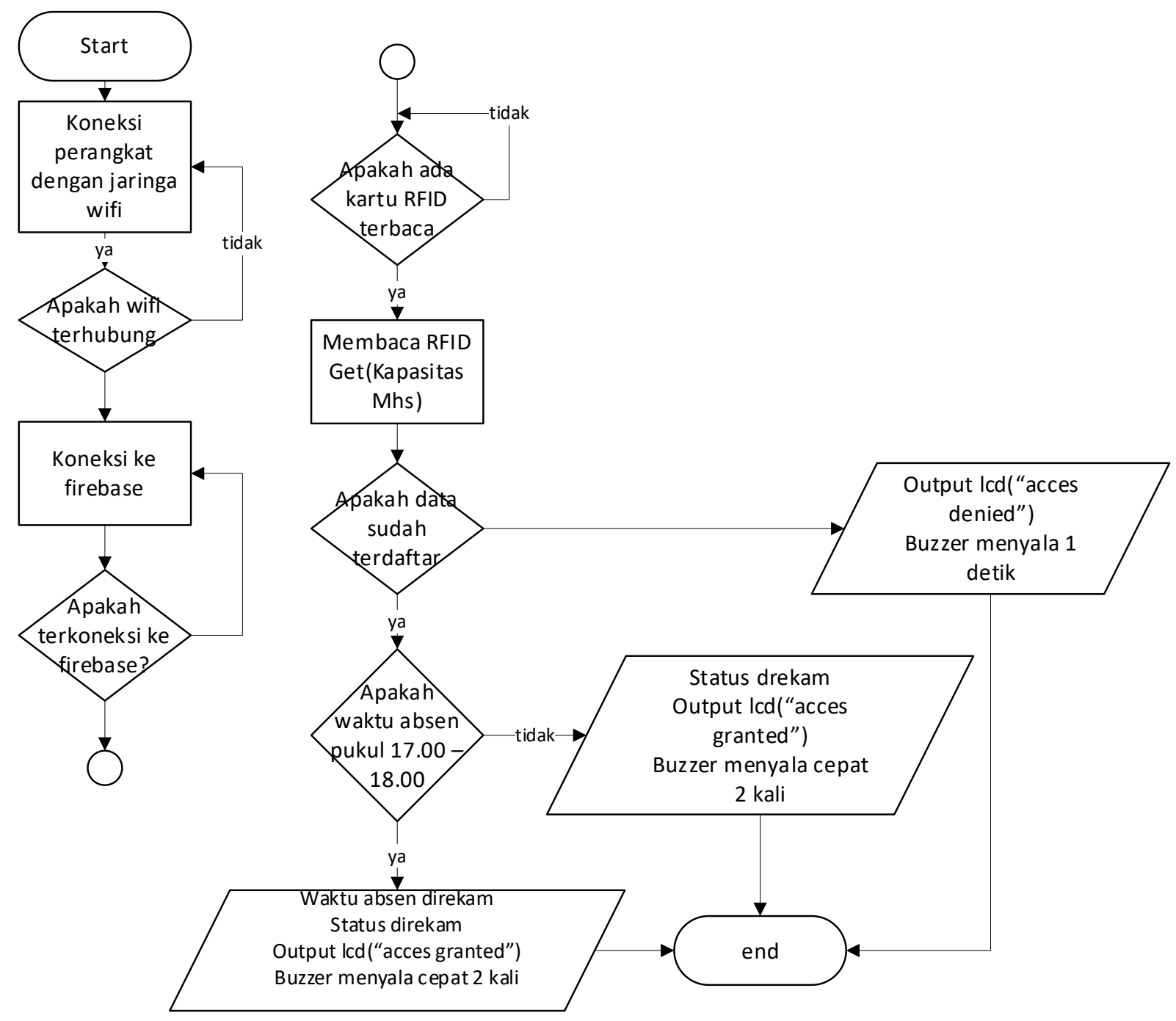

Gambar 6. Flowchart perangkat presensi 


\subsection{Realisasi Perangkat Keras}

Realisasi perangkat keras dilakukan dengan membuat printed circuit board (PCB) yang sesuai dengan perancangan skema elektronik, sehingga terdapat hasil berupa PCB yang akan dipakai untuk merakit rangkaian komponen yang akan digunakan. Perakitan dilakukan dengan merangkai semua komponen-komponen sistem pada PCB. Selanjutnya dilakukan tata peletakan komponen pada box hitam sebagai casing sistem dengan dimensi $12,5 \mathrm{~cm}$ x $8,5 \mathrm{~cm}$ x $5 \mathrm{~cm}$. Hasil rancangan tersebut ditunjukkan seperti pada Gambar 7.

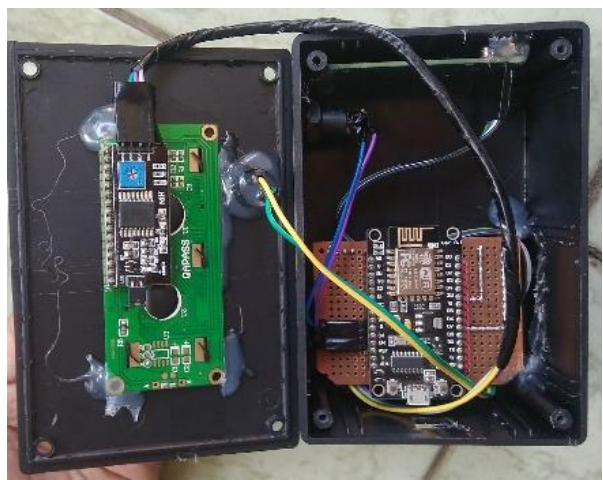

(a) Nampak dalam

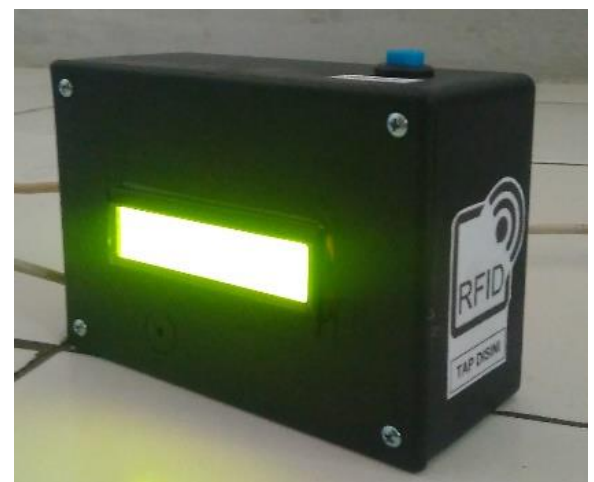

(b) Nampak luar

Gambar 7. Realisasi perangkat keras presensi

\section{HASIL DAN PEMBAHASAN}

\subsection{Pembacaan ID kartu RFID}

Pengujian pembacaan ID kartu RFID dilakukan pertama kali untuk mengetahui ID pada setiap kartu yang akan digunakan. Tabel 1 menunjukkan hasil pengujian dimana semua ID card sudah terdaftar pada sistem dan akan diterima aksesnya dengan output yang dihasilkan pada LCD adalah "access granted" dan output buzzer menyala dua kali. Sementara untuk ID yang tidak terdaftar pada sistem tidak diberikan akses oleh sistem presensi atau akses ditolak yang ditandai dengan output pada LDC yaitu "access denied" dan buzzer menyala selama 1 detik.

Tabel 1. Hasil pengujian kartu RFID pada perangkat presensi

\begin{tabular}{|l|l|l|}
\hline \multicolumn{1}{|c|}{ ID RFID } & \multicolumn{1}{c|}{ Status } & \multicolumn{1}{c|}{ Hasil } \\
\hline F9 29 D6 B2 & Terdaftar & Akses diterima \\
\hline 17 23 6B B4 & Terdaftar & Akses diterima \\
\hline DA B5 70 AD & Terdaftar & Akses diterima \\
\hline DA D7 2B A6 & Terdaftar & Akses diterima \\
\hline FC AE 73 18 & Terdaftar & Akses diterima \\
\hline 5A 16 44 85 & Tidak terdaftar & Akses ditolak \\
\hline
\end{tabular}

\subsection{Pengujian Jarak Pembacaan Kartu RFID}

Pengukuran jarak pembacaan ini dilakukan dengan mengukur jarak antara sistem presensi dengan kartu RFID. Pengukuran ini bertujuan untuk mengetahui batas pembacaan kartu RFID yang dapat dilakukan. Pada pengukuran ini, kami melakukan uji pembacaan dengan menggunakan dua ID kartu RFID yaitu dengan menggunakan kartu RFID dan tag RFID. Berdasarkan data hasil pengujian yang terdapat pada Tabel 2, pembacaan kartu RFID pada alat presensi baik itu pada tag RFID maupun kartu RFID pembacaan maksimalnya pada jarak $3 \mathrm{~cm}$.

Tabel 2. Pengukuran jarak pembacaan ID RFID

\begin{tabular}{|l|c|c|c|c|c|}
\hline \multirow{2}{*}{ Kartu } & \multicolumn{5}{|c|}{ Jarak (cm) } \\
\cline { 2 - 6 } & $\mathbf{0}$ (menyentuh casing) & $\mathbf{1}$ & $\mathbf{2}$ & $\mathbf{3}$ & $\mathbf{4}$ \\
\hline FC AE 73 18 (tag RFID) & $\sqrt{ }$ & $\sqrt{ }$ & $\sqrt{ }$ & $\sqrt{ }$ & $\mathrm{X}$ \\
\hline 17 23 6B B4 (kartu RFID) & $\sqrt{ }$ & $\sqrt{ }$ & $\sqrt{ }$ & $\sqrt{ }$ & $\mathrm{X}$ \\
\hline
\end{tabular}




\subsection{Pengujian Delay}

Pengukuran delay dilakukan dengan mengukur jeda waktu dari awal proses input ID kartu RFID melalui proses presensi, proses update data pada Firebase, sampai output yang dikeluarkan oleh sistem presensi. Adapun hasil pengujian delay untuk empat ID yang digunakan dapat dilihat pada Tabel 3 dengan analisis grafis pada salah satu kartu ditampilkan pada Gambar 8.

Tabel 3. Hasil pengujian delay dari proses input sampai output

\begin{tabular}{|c|c|c|c|c|c|c|c|c|}
\hline ID kartu & Waktu & $\begin{array}{c}\text { Jarak ke } \\
\text { WiFi }\end{array}$ & \multicolumn{5}{|c|}{ Delay (s) } & Rata-rata \\
\hline \multirow[t]{2}{*}{ FC AE 7318} & \multirow{4}{*}{$\begin{array}{l}\text { Sebelum } \\
\text { pukul } 17.00 \\
\text { WIB }\end{array}$} & $0-5 \mathrm{~m}$ & 2,48 & 2,57 & 2,22 & 2,63 & 2,89 & 2,558 \\
\hline & & $5-10 \mathrm{~m}$ & 2,58 & 2,75 & 2,76 & 2,71 & 2,57 & 2,674 \\
\hline \multirow[t]{2}{*}{$17236 \mathrm{~B} \mathrm{~B} 4$} & & $0-5 \mathrm{~m}$ & 2,3 & 2,23 & 2,94 & 2,69 & 2,76 & 2,584 \\
\hline & & $5-10 \mathrm{~m}$ & 2,67 & 2,74 & 2,47 & 2,79 & 2,4 & 2,614 \\
\hline \multirow[t]{2}{*}{ FC AE 7318} & \multirow{4}{*}{$\begin{array}{l}\text { Pada waktu } \\
\text { presensi } \\
17.00-19.00 \\
\text { WIB }\end{array}$} & $0-5 \mathrm{~m}$ & 3,73 & 3,15 & 3,00 & 3,2 & 4,3 & 3,476 \\
\hline & & $5-10 \mathrm{~m}$ & 5,78 & 4,82 & 3,25 & 3,25 & 4,34 & 4,288 \\
\hline \multirow[t]{2}{*}{1723 6B B4 } & & $0-5 \mathrm{~m}$ & 3,56 & 3,01 & 3,16 & 3,07 & 3,1 & 3,18 \\
\hline & & $5-10 \mathrm{~m}$ & 3,26 & 3,51 & 3,24 & 3,21 & 3,03 & 3,25 \\
\hline
\end{tabular}

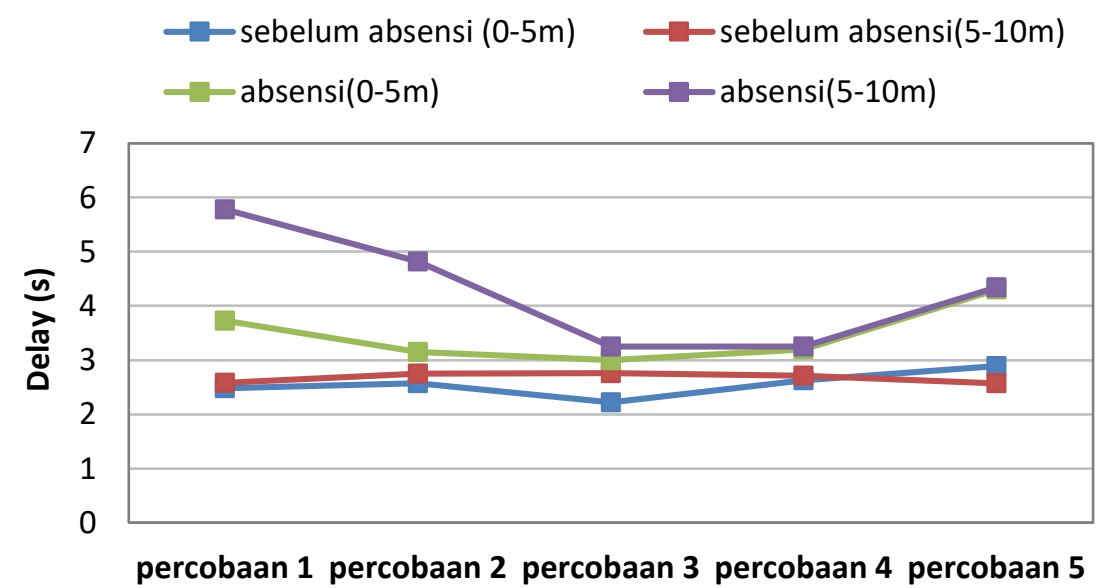

Gambar 8. Grafik percobaan pengukuran delay pada kartu RFID FC AE 7318

Berdasarkan grafik pada Gambar 8 terlihat jika percobaan pada kartu RFID dengan ID kartu FC AE 7318 didapatkan data waktu terkecil adalah selama 2,2 detik pada saat sebelum presensi dengan jarak ke pusat jaringan WiFi sejauh 0-5 m. Delay yang paling lama didapat ketika proses presensi dengan jarak sistem ke pusat jaringan WiFi adalah 5-10 m dengan delay waktu 5,78 detik. Hal ini menunjukan jika waktu ketika presensi dan sebelum presensi mempengaruhi kecepatan proses data dari awal sampai akhir. Selain itu, jarak dari sistem ke jaringan WiFi juga mempengaruhi proses update data. Semakin jauh jarak ke pusat jaringan WiFi, maka kualitas sinyal jaringan akan semakin buruk. Hal inilah yang mengakibatkan lambatnya proses pengiriman data dari sistem ke Firebase untuk melakukan update data.

\subsection{Integrasi Hardware Dengan Aplikasi}

Setiap user memiliki ID kartu yang berbeda-beda yang terdaftar di sistem presensi. Pada pengukuran parameter ini dilakukan dengan cara mengamati hasil input data ke Firebase ketika melakukan presensi dan mengamati aplikasi pada smartphone. Pengamatan ini bertujuan untuk melihat apakah aplikasi Android sudah terhubung dengan data input dari perangkat sistem presensi. Dalam hal ini, studi kasus yang akan diujikan adalah key "DiAsrama" pada Firebase yang akan dicocokkan dengan aplikasi Android dimana jika value dari key "DiAsrama" bernilai false maka icon pada aplikasi akan menjadi icon yang berarti user sedang berada di luar asrama. Sementara jika key bernilai true maka icon akan berubah yang berarti user sedang berada di dalam asrama. 
Tabel 4. Pengujian integrasi antara hardware dan software

\begin{tabular}{|c|c|c|c|c|c|c|}
\hline \multicolumn{6}{|c|}{ Percobaan ke- } & \multirow{2}{*}{ Rata-rata } \\
\hline & 1 & 2 & 3 & 4 & 5 & \\
\hline Delay (s) & 2,79 & 3,13 & 2,04 & 2,60 & 2,38 & 2,588 \\
\hline
\end{tabular}

Dari data yang didapat pada Tabel 4, waktu integrasi antara aplikasi dengan perangkat presensi tidak lebih dari 4 detik dengan waktu terlama ada pada uji coba ke-2 dengan waktu 3,13 detik dan waktu tercepat adalah 2,04 detik, serta rata-rata yang didapat dengan menjumlahkan semua delay waktu lalu dibagi dengan jumlah percobaan adalah sebesar 2,588 detik.

\subsection{Pengujian Aplikasi}

Gambar 9 merupakan tampilan hasil rekap presensi pada aplikasi dimana pada Gambar 9(a) merupakan tampilan aplikasi pada sisi user dan Gambar 9(b) merupakan tampilan rekap presensi pada sisi admin.
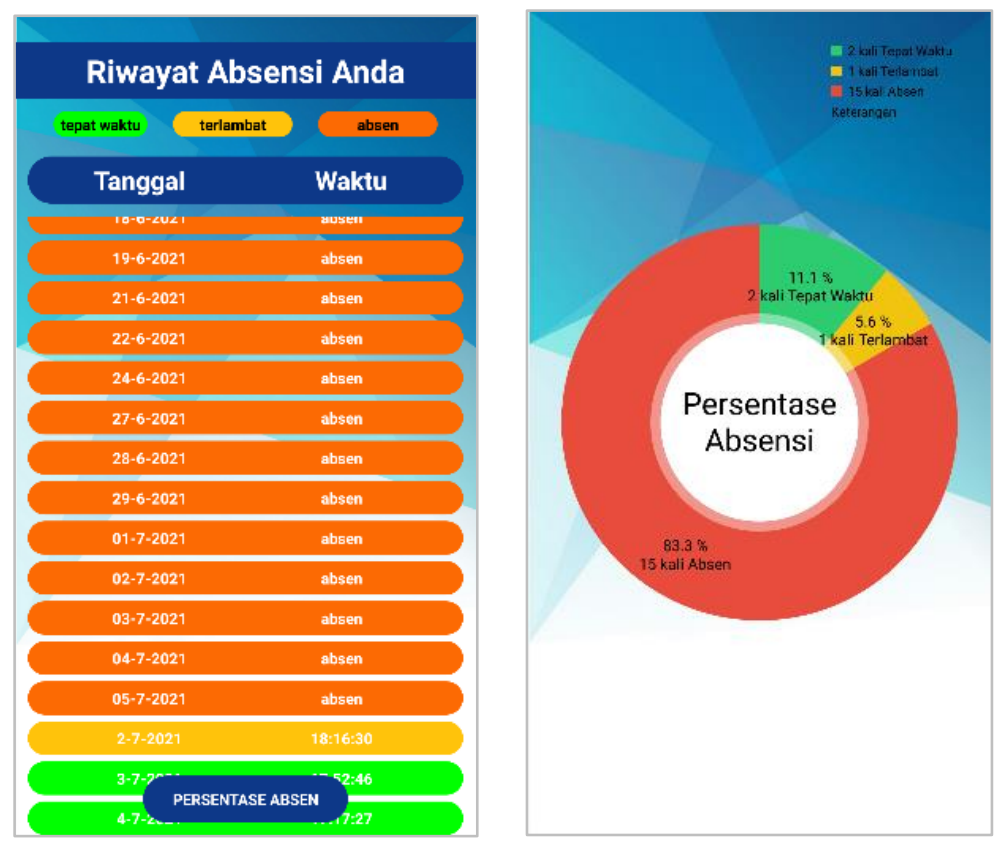

(a) Tampilan rekap presensi di user

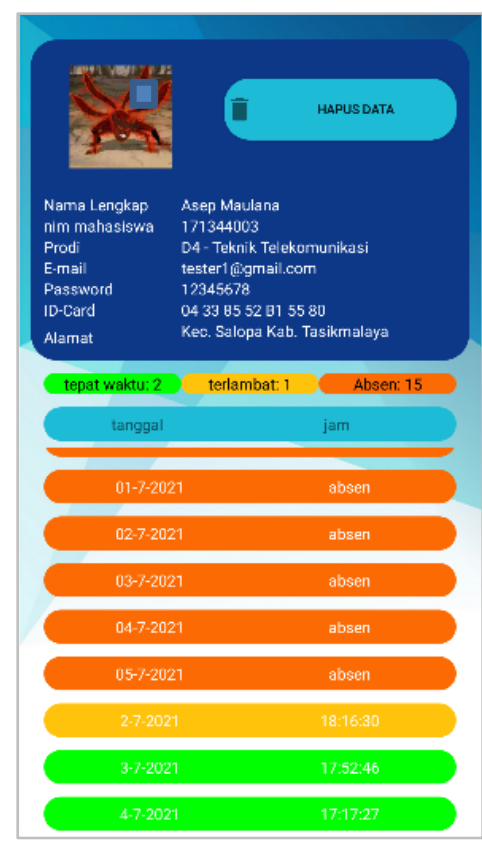

(b) Tampilan rekap presensi di admin

\section{Gambar 9. Tampilan hasil rekap presensi pada aplikasi}

Data pada Tabel 5 merupakan data hasil pengujian fungsi aplikasi yang dilakukan oleh responden dengan tiga versi Android yang berbeda, yaitu versi Android 10, 8.0, dan 7.0. Berdasarkan data yang didapat, fungsi-fungsi menu aplikasi dapat berjalan dengan lancar pada perangkat responden. Berdasarkan data yang didapat pada Tabel 6 yang merupakan data kepuasan responden terhadap aplikasi dimana jumlah keseluruhan responden adalah sebanyak 4. Responden tersebut dipilih karena pernah menjadi anggota dan admin di asrama sehingga pengambilan data tersebut dapat sesuai dengan pengalaman responden saat berada di asrama. Setiap responden memberikan tanggapan terhadap 6 aspek nilai yaitu kemudahan aplikasi, tampilan aplikasi, bahasa yang digunakan, penyajian data dan informasi, user experience, dan pendapat keseluruhan. Hasilnya survei dengan diuji dari total 24 poin tanggapan yang diberikan kepada responden, 8,33\% menyatakan cukup, 83,33\% menyatakan baik, dan $8,33 \%$ menyatakan sangat baik. Terdapat beberapa saran dari responden untuk membuat aplikasi lebih baik lagi seperti penambahan fitur pada aplikasi seperti pemantauan kondisi kesehatan mahasiswa, daftar inventaris asrama, dan fitur-fitur lain yang diperlukan. Selain itu terdapat pula saran penambahan fitur chat antar anggota supaya bisa bicara bila ada sesuatu yang perlu dibicarakan. Sedangkan untuk bagian hardware sendiri, perlu adanya penambahan sistem keamanan seperti 
penambahan akses CCTV pada aplikasi untuk memantau secara langsung keadaan asrama, penggunaan sensor yang digunakan dapat diganti dengan sensor sidik jari, dan penambahan sensor suhu tanpa kontak untuk monitoring suhu anggota asrama. Selain itu, perlu adanya indikator pada perangkat presensi untuk cara kerja sensor apakah sensor berjalan atau tidak yang terintegrasi dengan aplikasi sehingga pengurus dapat mengawasi apakah sensor pembacaan ID card berjalan lancar atau tidak.

Tabel 5. Uji aplikasi yang dilakukan oleh responden

\begin{tabular}{|c|c|c|c|}
\hline \multirow{2}{*}{ Pengujian } & \multicolumn{3}{|c|}{ Versi Android } \\
\hline & Android 10 & 7.0 Nougat & 8.0 Oreo \\
\hline Masuk menu login & $\sqrt{ }$ & $\sqrt{ }$ & $\sqrt{ }$ \\
\hline Registrasi pengguna baru & $\sqrt{ }$ & $\sqrt{ }$ & $\sqrt{ }$ \\
\hline $\begin{array}{l}\text { Mengakses profil dan mengedit } \\
\text { profil }\end{array}$ & $\sqrt{ }$ & $\sqrt{ }$ & $\sqrt{ }$ \\
\hline Mengakses riwayat presensi & $\sqrt{ }$ & $\sqrt{ }$ & $\sqrt{ }$ \\
\hline $\begin{array}{l}\text { Mengakses menu paket dan } \\
\text { konfirmasi paket }\end{array}$ & $\sqrt{ }$ & $\sqrt{ }$ & $\sqrt{ }$ \\
\hline $\begin{array}{l}\text { Mengakses menu laporan dan } \\
\text { mengirim laporan }\end{array}$ & $\sqrt{ }$ & $\sqrt{ }$ & $\sqrt{ }$ \\
\hline Mengakses menu reminder & $\sqrt{ }$ & $\sqrt{ }$ & $\sqrt{ }$ \\
\hline Melakukan logout & $\sqrt{ }$ & $\sqrt{ }$ & $\sqrt{ }$ \\
\hline Set presensi & $\sqrt{ }$ & $\sqrt{ }$ & $\sqrt{ }$ \\
\hline $\begin{array}{l}\text { Mengakses menu presensi dan } \\
\text { melihat detail user }\end{array}$ & $\sqrt{ }$ & $\sqrt{ }$ & $\sqrt{ }$ \\
\hline Masuk menu menambahkan paket & $\sqrt{ }$ & $\sqrt{ }$ & $\sqrt{ }$ \\
\hline $\begin{array}{l}\text { Masuk menu laporan dan } \\
\text { menanggapi laporan } u s e r\end{array}$ & $\sqrt{ }$ & $\sqrt{ }$ & $\sqrt{ }$ \\
\hline $\begin{array}{l}\text { Masuk menu reminder, menambah, } \\
\text { mengedit ,dan menghapus reminder }\end{array}$ & $\sqrt{ }$ & $\sqrt{ }$ & $\sqrt{ }$ \\
\hline
\end{tabular}

Tabel 6. Penilaian responden

\begin{tabular}{|l|c|c|c|c|}
\hline \multirow{2}{*}{ Pertanyaan } & \multicolumn{4}{c|}{ Hasil Penilaian } \\
\cline { 2 - 5 } & Kurang & Cukup & Baik & Sangat Baik \\
\hline Apakah aplikasi mudah digunakan? & - & - & III & I \\
\hline $\begin{array}{l}\text { Apakah menu tampilan aplikasi mudah } \\
\text { dipahami? }\end{array}$ & - & - & IIII & - \\
\hline $\begin{array}{l}\text { Apakah penggunaan bahasa pada aplikasi } \\
\text { mudah dimengerti? }\end{array}$ & - & - & III & I \\
\hline $\begin{array}{l}\text { Bagaimana penyajian informasi pada } \\
\text { aplikasi ini? }\end{array}$ & - & - & IIII & - \\
\hline $\begin{array}{l}\text { Bagaimana user experience dari tampilan } \\
\text { aplikasi? }\end{array}$ & - & - & IIII & - \\
\hline $\begin{array}{l}\text { Bagaimana pendapat anda tentang } \\
\text { keseluruhan tampilan aplikasi ini? }\end{array}$ & - & II & II & - \\
\hline Total & - & 2 & 20 & 2 \\
\hline Presentase $=($ Total/24)*100 & - & $8,33 \%$ & $83,33 \%$ & $8,33 \%$ \\
\hline
\end{tabular}

\section{KESIMPULAN}

Aplikasi manajemen asrama berbasis Android "Asrama-Ku" dapat berjalan secara lancar pada beberapa perangkat yang telah diuji dan berjalan dengan baik. Perangkat sistem presensi yang terintegrasi dengan aplikasi Android dapat merekam data presensi mahasiswa berjalan dengan lancar dengan waktu integrasi tidak lebih dari 3 detik pada waktu sebelum presensi dan pada waktu presensi maksimal waktu yang dibutuhkan adalah tidak lebih dari 6 detik. Hasil survei terhadap responden yang didapat dari total 24 poin tanggapan, 8,33\% menyatakan cukup, 83,33\% menyatakan baik, dan $8,33 \%$ menyatakan sangat baik. Dengan adanya aplikasi ini, penghuni asrama baik itu pengurus 
maupun anggota akan lebih dimudahkan dalam proses manajemen kegiatan asrama. Saran untuk penelitian selanjutnya yaitu aplikasi dapat dikembangkan sesuai dengan beberapa saran dan rekomendasi dari responden saat melakukan survei.

\section{REFERENSI}

[1] Politeknik Negeri Bandung, [Online]. Available: http://www.polban.ac.id/upload/PERATURAN \%20AKADEMIK\%20MAHASISWA\%202011.pdf.

[2] M. R. Sali and L. N. Amali, "Aplikasi Kajian Islam Dengan Teknologi Firebase Realtime Database," Jambura Journal of Informatics, vol. 1, no. 1, pp. 1-8, 2019.

[3] G. R. Payara and R. Tanone, "Penerapan Firebase Realtime Database pada Prototype Aplikasi Pemesanan Makanan Berbasis Android," Jurnal Teknik Informatika dan Sistem Informasi (JUTISI), vol. 4, no. 3, pp. 397-406, 2018.

[4] E. K. Siagian, A. Mulyana, and A. Hartaman, "Perancangan Sistem Informasi dan Pengelolaan Asrama Putri Universitas Telkom Berbasis Web dan Aplikasi Android," e-Proceeding of Applied Science, vol. 6, no. 2, pp. 2432-2441, 2020.

[5] Y. Darnita and M. Muntahanah, "Rancang Bangun Aplikasi Mobile Penjadwal Perkuliahan Dengan Firebase Dengan Realtime Notification,” Jurnal Pseudocode, vol. 8, no. 1, pp. 58-65, 2021.

[6] G. Santoso and S. Hani, "Perancangan Sistem Doorlock Menggunakan RFID dan Android Berbasis Arduino Nano," Prosiding Seminar Nasional Aplikasi Sains \& Teknologi (SNAST), 2018, pp. B19-B28.

[7] K. P. Aji and U. Darusalam, "Perancangan Sistem Presensi Untuk Pegawai Dengan RFID Berbasis IoT Menggunakan NodeMCU ESP8266," Journal of Information Technology and Computer Science (JOINTECS), vol. 5, no. 1, pp. 25-32, 2020.

[8] A. N. Asyikin, B. Suriansyan, and A. H. Heka, "Prototype Mesin Absensi Berbasis Internet of Things Menggunakan E-KTP Studi Kasus di Simpadu Politeknik Negeri Banjarmasin," Prosiding SNRT (Seminar Nasional Riset Terapan), 2019, pp. A48-A57.

[9] A. Sopa, H. M. Saputra, and A. Nurhakim, "Sistem Kehadiran Menggunakan RFID pada E-KTP Berbasis Internet of Things Attendance System using RFID on E-KTP Based on Internet of Things," Seminar Nasional Teknik Elektro (SENTER), 2019, pp. 412-418.

[10] S. S. Chandra, R. Lim, and H. Khoswanto "Sistem Kendali Akses Pintu Menggunakan RFID dan Aplikasi Android pada Laboratorium Sistem Kontrol," Jurnal Teknik Elektro, vol. 11, no. 1, pp. 17-22, 2018.

[11] E. Prasetiyo and S. Ariwibowo, "Sistem Absensi Berbasis RFID," Prosiding Seminar Nasiolnal Teknik Elektro, vol. 4, no. 1, pp. 278-281, 2019. 